\title{
Neurocalcin-delta: a potential memory-related factor in hippocampus of obese rats induced by high-fat diet.
}

\author{
Wei-Wei Ma ${ }^{1}$, Bing-Jie Ding ${ }^{2}$, Lin-Hong Yuan ${ }^{1}$, Lei Zhao ${ }^{3}$, Huan-Ling Yu ${ }^{1}$, Yuan-di Xi ${ }^{1}$, Rong Xiao ${ }^{1}$
}

\begin{abstract}
1. School of Public Health, Beijing Key Laboratory of Enviromental Toxicology, Capital Medical University, Beijing 100069, China.

2. Department of Clinical Nutrition Beijing Friendship Hospital, Capital Medical University.

3. Department of Molecular Physiology and Biophysics, Holden Comprehensive Cancer Center, University of Iowa Carver College of Medicine, Iowa City, IA 52242, USA
\end{abstract}

\begin{abstract}
Introduction: Aberrant protein expression within the hippocampus has recently been implicated in the pathogenesis of obesity-induced memory impairment.

Objectives: The objective of the current study was to search for specific memory-related factors in the hippocampus in obese rats.

Methods: Sprague-Dawley (SD) rats were fed either a high-fat (HF) diet or normal-fat (NF) diet for 10 weeks to obtain the control (CON), diet-induced obese rats (DIO) and diet-resistant (DR) rats. D-galactose was injected subcutaneously for 10 weeks to establish model (MOD) rats with learning and memory impairment. After the hippocampus of the rats sampling, the proteome analysis was conducted using two-dimensional get electrophoresis (2-DE) combined with peptide mass fingerprinting (PMF).

Results: We found 15 differential proteins that expressed in the hippocampus in rats induced by HF diet from the 2-DE map. In addition, Neurocalcin-delta (NCALD) was nearly down-regulated in the DR rats compared with CON rats and MOD rats, which was further confirmed by Western blot, real-time PCR and ELISA results.

Conclusion: Our data demonstrates that the differential memory-related proteins were a reflection of the HF diet, but not potential factors in obesity proneness or obesity resistance. Furthermore, NCALD is proved to be a potential hippocampus-memory related factor related to obesity.
\end{abstract}

Keywords: Diet-induced obesity; diet-resistant; high fat diet; neurocalcin-delta; proteome.

DOI: https://dx.doi.org/10.4314/ahs.v17i4.32

Cite as: Ma W-W, Ding B-J, Yuan L-H, Zhao L, Yu H-L, Xi Y-d, Xiao R. Neurocalcin-delta: a potential memory-related factor in hippocampus of obese rats induced by high-fat diet. Afri Health Sci.2017;17(4):1211-1221. https:// dx.doi.org/10.4314/ahs.v17i4.32

\section{Introduction}

Obesity, a chronic metabolic disease, represents one of the most serious public health and societal problems for the coming decades ${ }^{1}$, which affects greater than 35\% of the population of U.S and an estimated 670 million

\section{Corresponding author:}

Rong Xiao,

School of Public Health, Beijing Key Laboratory of

Enviromental Toxicology, Capital Medical University,

Beijing 100069, China.

Tel: 86-010-83911512

Fax: 86-010-83911512

Postal address: No.10Xitoutiao,

You An Men, Beijing 100069, P.R.China

E-mail: xiaor1222@163.com, xiaor22@,ccmu.edu.cn people worldwide ${ }^{2}$. Obesity has been associated with a multitude of diseases, including cardiovascular disease, diabetes, hypertension, and certain cancers ${ }^{3-5}$. In addition, recent evidence has also highlighted that obesity is associated with cognitive impairments and with an increased risk of developing dementia and alzheimer's disease (AD) later in life ${ }^{6-8}$. Epidemiological studies suggest that presence of obesity increases the incidence of numerous neuro-degenerative conditions including $\mathrm{AD}^{8,9}$. The rate of cognitive dysfunction happened in obese people was significantly higher than that of normal-weighted peo$\mathrm{ple}^{10-13}$. Such results are essential in understanding the mechanisms for the role of obesity in modulating neuro-degenerative processes ${ }^{14}$. Rodent studies indicate that Sprague-Dawley (SD) rats showed impaired learning and cognitive functions after being fed with the high-fat (HF) diets $^{15}$, complicated with damaged neurons in the hippo-

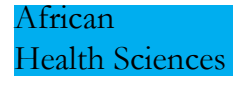

1211
@ $2017 \mathrm{Ma}$ et al; licensee African Health Sciences. This is an Open Access article distributed under the termsof the Creative commons Attribution License (https://creativecommons.org/licenses/by/4.0), which permits unrestricted use, distribution, and reproduction in any medium, provided the original work is properly cited. 
campus. This result is consistent with our previous studies $^{16,17}$.

Hippocampus-dependent memory appears to be particularly vulnerable to high-fat diets and these deficits can occur rapidly and even prior to weight gain ${ }^{18}$. As the brain cannot synthesize or store energy reserves, foods provide its immediate source of energy to the brain and thereby may influence its structure and functions ${ }^{19}$. Several interactive processes have been proposed to underlie cognitive declines related to $\mathrm{HF}$ diets, including oxidative stress and inflammation ${ }^{20}$, increased blood brain barrier permeability ${ }^{21,22}$, reduced neurotrophic factors ${ }^{23}$, and insulin insensitivity ${ }^{24}$. Among the pathophysiology of obesity, obesity-induced oxidative stress has been suggested as a potential link between obesity-related metabolic disturbances and chronic diseases. However, the factors related to obesity-induced impairments remain largely unknown. Aberrant protein expression within the hippocampus has recently been implicated in the pathogenesis of obesity-induced memory impairments. Primarily, proteomic techniques are used to examine differences in protein expression in the hippocampus related to obesity. The most traditional and most widely used proteomic method associated with obesity is the two-dimensional polyacrylamide gel electrophoresis (2D-PAGE). In previous researches in obesity, the proteomics assays have been used in the detection of protein expression profiles in serum ${ }^{25,26}$, $\operatorname{adipocytes}^{27}$, and skeletal muscle ${ }^{28}$. However, there is a paucity of proteomic data on the brain, especially the hippocampus, during obesity. In this study, we reported the evidence of obesity-induced alterations in expression of memory-associated proteins in the hippocampus of obese rats, and thus offered a novel mechanism by which protein expression within the hippocampus is suppressed during obesity.

\section{Methods}

\section{Animals and diets}

All experimental procedures were approved by the Animal Ethics Committee of Capital Medical University and conducted in compliance with the animal-use guidelines. A total of 50 male Sprague-Dawley rats (body weight 140 $\sim 160 \mathrm{~g}$; SPF degree) were purchased from Academy of Military Medical Sciences (Beijing, China). All of the rats were housed in plastic boxes individually at $20 \sim 23^{\circ} \mathrm{C}$ with food and water available. Rats were fed with standard laboratory chow for the first week to adapt to the new environment. In the following experimental period, rats were given either a normal-fat (NF) diet (345.3 $\mathrm{kcal} / 100 \mathrm{~g}, 10 \%$ fat content) or a high-fat (HF) diet (435.96 kcal/100 g, 40\% fat content). The HF and NF diet formulations (SPF degree) were also purchased form Academy of Military Medical Sciences (Beijing, China).

\section{Experimental protocol}

After the acclimatisation period, 10 rats were randomly assigned to receive a NF diet according to their body weights, and D-galactose (120 mg/kg.d) was injected subcutaneously through the back of the neck for 10 weeks to establish the model (MOD) rats. Another 40 rats were placed on a HF diet for 2 weeks and weighed for body weight. The 10 intermediate weight gainers were then switched back to a NF diet and were designated as controls (CON). The other 30 rats were continually fed with a HF diet continually, and 8 weeks later the upper tertile $(\mathrm{n}=10)$ in gained body weight were designated as diet-induced obese rats (DIO), and the lower tertile $(n=10)$ in gained body weight were referred to as diet-resistant (DR). Those in the middle tertile $(\mathrm{n}=10)$ were removed from the experiment. The rats were then anesthetized and the blood samples were collected from the heart. The hippocampus of the brain was also all collected for all rats.

\section{2-D gel electrophoresis and peptide mass finger- printing (PMF) by MALDI-TOF-MS}

For 2-DE, equal amounts of the hippocampus tissues of each animal within a group $(n=5)$ were combined to yield the group sample. The hippocampus was weighed and ground into power. The RIPA buffer was added to the powder at $150 \mathrm{mg} / \mathrm{ml}$. Then $50 \mathrm{ug} / \mathrm{ml}$ RNase and 200 $\mathrm{ug} / \mathrm{ml}$ DNase were added. Then the solution was placed at $4^{\circ} \mathrm{C}$ for 15 minutes and centrifuged for 60 minutes at $4^{\circ} \mathrm{C}, 15000 \mathrm{~g}$. The supernates were collected and the protein content was measured with the BCA assay. $10 \mathrm{mg} /$ $\mathrm{ml}$ of total protein was diluted to $100 \mu \mathrm{l}$ with rehydration solution (8 M urea, $2 \mathrm{M}$ thiourea, $4 \%$ (w/v) CHAPS, $65 \mathrm{mM}$ DTT and $0.5 \%$ immobilized $\mathrm{pH}$ gradient (IPG) buffer) and applied onto 17-cm, pH3-10 linear IPG strips (Aersham Biosciences, Sweden). The strips were rehydrated for 1 hour at $20^{\circ} \mathrm{C}$. The proteins were then focused on the IPGphor system according to the manufacturer's protocol. The strips were equilibrated for 15 min in a solution containing 65 mM DT'T, 6 M urea, 20\% 
(w/v) glycerol, 2\% (w/v) SDS, and $375 \mathrm{mM}$ Tris-HCl ( $\mathrm{pH}$ 8.8). The second equilibration step was carried out for $15 \mathrm{~min}$ in the same solution except for DTT, which was replaced by $2.5 \%(\mathrm{w} / \mathrm{v})$ iodoacetamide. Separation of proteins by 2-DE was carried out with $12 \%$ SDS-polyacrylamide gel without stacking gel at a constant current of $16 \mathrm{~mA} /$ gel for the initial $15 \mathrm{~min}$ and $32 \mathrm{~mA} /$ gel thereafter until the bromphenol blue dye marker reached the bottom of the gel. Proteins were visualized by coomassie blue staining. The stained gels were scanned and analyzed using an Image Master 2D Platinum 6.0. Protein spots were considered differentially expressed if a significant difference in the normalized spot volume was observed between different groups.

The strips in fresh CCB-stained gel were excised and plated into a 96-well microtitre plate. Excised slices were firstly destained twice with $60 \mu \mathrm{l}$ of $50 \mathrm{mM} \mathrm{NH}_{4} \mathrm{HCO}_{3}$ and $50 \%$ acetonitrile and then dried twice with $60 \mu \mathrm{l}$ of acetonitrile. Afterwards, the dried pieces of gels were incubated in ice-cold digestion solution (trypsin $12.5 \mathrm{ng} / \mu \mathrm{l}$ and $20 \mathrm{mM} \mathrm{NH}_{4} \mathrm{HCO}_{3}$ ) for $20 \mathrm{~min}$ and then transferred into a $37^{\circ} \mathrm{C}$ incubator for digestion overnight. Finally, peptides in the supernatant were collected after extraction twice with $60 \mu$ l extract solution (5\% formic acid in 50\% acetonitrile). The peptide solution described above was dried. The $0.8 \mu \mathrm{l}$ matrix solution $(5 \mathrm{mg} / \mathrm{ml} \alpha$-cyano-4-hydroxy-cinnamic acid diluted in $0.1 \%$ TFA, $50 \% \mathrm{ACN}$ ) was added to dissolve it. Then the mixture was spotted on a MALDI target plate (AB SCIEX). MS analysis of peptide was performed on an AB SCIEX 5800 TOF/TOF. The UV laser was operated at a $400 \mathrm{~Hz}$ repetition rate with a wave length of $355 \mathrm{~nm}$. The accelerated voltage was operated at $20 \mathrm{kV}$, and mass resolution was maximized at $1600 \mathrm{Da}$. All acquired spectra of samples were processed using the TOF/TOF Explorer TM Software (AB SCIEX) in a default mode. The data were searched by GPS Explorer (V3.6) with the search engine MASCOT (2.3). The searching parameters were as follows: the database for rat, trypsin digestion with one missing cleavage, MS tolerance was set at $100 \mathrm{ppm}$, MS/MS tolerance of 0.6 Da. The obtained PMFs were used to search through the Swiss-Prot and NCBInr database by the Mascot search engine (http://www.matrixscience.co.uk). Protein with a score greater than 63 were considered to be significant $(\mathrm{p}<0.05)$.

\section{Real-time PCR analysis}

The total mRNA from rat brain was purified using the SV Total RNA Isolation system (Beijing ComWin Biotech Co.,Ltd., China). The mRNA expression levels of NCALD, were analyzed by real-time PCR. Reverse transcription (RT) was performed with a Reverse Transcription System (Beijing ComWin Biotech Co.,Ltd., China). Briefly, double-stranded DNA was synthesized from $1 \mu \mathrm{g}$ of total RNA and used as a template for the real-time PCR. The sequences of the forward and reverse are shown in Table 2. The real-time PCR reaction system included $0.4 \mu \mathrm{l}$ of forward primer $(10 \mu \mathrm{M}$ solution), 0.4 $\mu \mathrm{l}$ of reverse primer $(10 \mu \mathrm{M}$ solution), $10 \mu \mathrm{l}$ of SYBR Green PCR Master Mix, 7.2 $\mu$ l of nucleus-free water and $2 \mu \mathrm{l}$ of cDNA, reaching a total volume of $20 \mu \mathrm{l}$ in each well. Real-time PCR experiments were performed on a CFX Connect Real-Time PCR Detection System as follows: $60^{\circ} \mathrm{C}$ for $2 \mathrm{~min}$, an initial denaturation at $95^{\circ} \mathrm{C}$ for $10 \mathrm{~min}$, and 45 cycles including strand separation at $95^{\circ} \mathrm{C}$ for $10 \mathrm{~s}$. The housekeeping gene $18 \mathrm{~S}$ rRNA served as a reference for standardization. All of the measurements were performed in duplicates, and the experiment were repeated once. Fold changes were calculated using the $\mathrm{Ct}$ (Ct of the target gene - Ct of the housekeeping gene) method where the fold change is equal to $2^{-\mathrm{Ct}}$ for the gene analysis level.

\section{Western blot analysis}

The hippocampus of the brain in different treatment groups were collected and grinded by tissue grinder in RIPA buffer for 45 minutes at $4{ }^{\circ} \mathrm{C}$, then the homogenized tissues were centrifuged at $15,000 \mathrm{rpm}$ for 20 minutes. The supernatant was separated and collected for protein analysis. The protein concentration was determined by using the BCA protein assay kit (Pierce Biotechnology, USA). Protein samples were loaded and separated by $10 \%$ SDS-acrylamide gel electrophoresis and wet transferred to polyvinylidene fluoride blots at the voltage of $60 \mathrm{v}$ for 2 hours. The membrane was blocked by fresh blocking buffer (Tris-buffered saline containing 5\% skim milk) at room temperature for 1 hour. Immunoblots were performed with appropriate antibodies. Primary antibody (diluted in 1:1000 with TBST and 1\% non-fat dry milk) for anti-Neurocalcin-delta (NCALD) (Cell Signaling Biotechnology, USA), was incubated with membrane for 12 hours at $4^{\circ} \mathrm{C}$. $\beta$-actin $(1: 1000$, Cell Signaling Biotechnology, USA) was used as a housekeeping reference. The 
proper secondary antibodies were incubated for 1 hour at room temperature. The blots were washed for three times with TBST buffer and protein bands were visualized by using an alkaline phosphatase reaction kit according to the manufacturer's instructions. The FluorChem FC2 software (Alpha Innotech, America) was used to analyze the gray scale value of the protein bands in each group.

\section{ELISA assay}

NCALD protein levels in the hippocampus tissue homogenates of rat brain were measured using the Enzyme-linked Immunosorbent Assay Kits (Enzyme-linked biological technology, Shanghai, China) according to the manufacturer's instruction. Briefly, the tissues were minced in ice-cold PBS $(0.01 \mathrm{~mol} / \mathrm{L}, \mathrm{pH} 7.0-7.2)$, and then the homogenates were centrifugated for 20 minutes at $15000 \mathrm{rpm}$. The homogenate $(10 \mu \mathrm{l})$ and sample diluents (40 ul) were added into the appropriate 96-well plate and incubated for 30 minutes at $37^{\circ} \mathrm{C}$. After washing the 96-well plate for 5 times, the enzyme (50 ul) was added and incubated for 30 minutes at $37^{\circ} \mathrm{C}$. After washing the 96-well plate for 5 times again, the color-developing agent $\mathrm{A}$ and $\mathrm{B}$ were added respectively, and incubated for 10 minutes at $37^{\circ} \mathrm{C}$. Finally, the stop solution was also added and the absorption was measured at $450 \mathrm{~nm}$ using the microplate reader (Tecan company, Switzerland) immediately. The concentration of NCALD was calculated.

\section{Statistical analysis}

Data were presented as mean \pm standard error (S.E) and analyzed with the software SPSS 13.0. The means among groups were compared with one-way ANOVA followed by LSD post-hoc test. A two-tailed $\mathrm{p}<0.05$ was considered to be significantly different.

\section{Results}

\section{2-D gel analysis}

At the end of week 10, leukemia-associated phosphoprotein p18 (Lap 18) and $\beta$-actin were down-regulated in the hippocampus of DIO and DR rats compared with CON rats and MOD rats (all $\mathrm{p}<0.05)$. Protein canopy homo$\log 2$ (Cnpy2) and Neurocalcin-delta (NCALD) were down-regulated in DR rats compared with $\mathrm{CON}$ and MOD rats, and NCALD was down-regulated in DIO rats compared with $\mathrm{CON}$ rat $(\mathrm{p}<0.05)$. Heterogeneous nuclear ribonucleo protein $\mathrm{K}$ (Hnrnpk) was down-regulated, while ubiquinol-cytochrome c reductase was up-regulated in DIO rats compared with CON and MOD rats (both $\mathrm{p}<0.05)$. Neuron-specific calcium-binding protein hippocalcin (Hpca) was down-regulated, while dihydropyrimidinase-related protein 2 (Dpysl2) and gamma-actin (Atcg1) were up-regulated in DR rats compared with $\mathrm{CON}$ and MOD rats (all $\mathrm{p}<0.05)$. Down-regulated tubulin beta-2A chain (Tubb2a) and up-regulated serum albumin precursor (Alb) were observed in the DR rats compared with other groups of rats (all $\mathrm{p}<0.05)$. Tubulin alpha-1B chain (Tuba1b) was up-regulated in DIO rats compared with DR rats $(p<0.05)$. Ubiquitin carboxy-terminal hydrolase L1 (Uchl1) was down-regulated and malate dehydrogenase (Mdh2) was up-regulated in DIO rats compared with MOD rats (both $\mathrm{p}<0.05$ ). Dismutase was downregulated in both DIO and DR rats compared with CON rats (both $\mathrm{p}<0.05)$. The differentially expressed spots are presented in Figure 3 and the identified proteins are listed in Table 1. 
Table 1 The identified protein in the hippocampus of DIO and DR rat.

\begin{tabular}{|c|c|c|c|c|c|c|}
\hline \multirow{2}{*}{$\begin{array}{l}\text { Spot } \\
\text { No. }\end{array}$} & \multirow[t]{2}{*}{ Identified Protein } & \multicolumn{4}{|c|}{ Relative value of the protein expression } & \multirow[t]{2}{*}{ Gi accession } \\
\hline & & $\mathrm{CON}$ & MOD & $\mathrm{DIO}$ & DR & \\
\hline 1 & $\begin{array}{l}\text { leukemia-associated } \\
\text { phosphoprotein p18 }\end{array}$ & 779.9 & 649.9 & $78.5^{\mathrm{ab}}$ & $13.9^{\mathrm{ab}}$ & 134974 \\
\hline 2 & protein canopy homolog 2 & 3128.2 & $987.2^{\mathrm{a}}$ & $373.9^{\mathrm{a}}$ & $13.9^{\mathrm{ab}}$ & 117606182 \\
\hline 3 & $\begin{array}{l}\text { heterogeneous nuclear } \\
\text { ribonucleoprotein K }\end{array}$ & 204.7 & 319.4 & $9.9^{\mathrm{ab}}$ & 225.5 & 48429097 \\
\hline 4 & neurocalcin-delta & 1653 & 1178.4 & $573^{a}$ & $128.9^{\mathrm{ab}}$ & 81909955 \\
\hline 5 & $\begin{array}{l}\text { neuron-specific calcium- } \\
\text { binding protein hippocalcin }\end{array}$ & 4016.7 & 4892.9 & 1997.7 & $640.1^{\text {ab }}$ & 8850221 \\
\hline 6 & Tubulin beta-2A chain & 5293.1 & 5797.1 & 5440.8 & $1332.1^{\mathrm{abc}}$ & 144587401 \\
\hline 7 & $\begin{array}{l}\text { ubiquinol-cytochrome c } \\
\text { reductase }\end{array}$ & 167.4 & 259.8 & $1834.4^{\text {ab }}$ & $406.5^{\mathrm{a}}$ & 149045287 \\
\hline 8 & $\begin{array}{l}\text { ubiquitin carboxyl-terminal } \\
\text { hydrolase isozyme L1 }\end{array}$ & 8.4 & $399.3^{\mathrm{a}}$ & $31.3^{b}$ & 67.9 & 68844977 \\
\hline 9 & $\begin{array}{l}\text { dihydropyrimidinase-related } \\
\text { protein } 2\end{array}$ & 1161.7 & 1298.3 & 2997.1 & $3650.5^{\mathrm{ab}}$ & 1351260 \\
\hline 10 & dismutase & 2038.7 & 1674.3 & $1002.8^{\mathrm{a}}$ & $204^{\mathrm{a}}$ & 818029 \\
\hline 11 & malate dehydrogenase & 1646.8 & $614.5^{\mathrm{a}}$ & $3253.4^{b}$ & 1639.5 & 81861572 \\
\hline 12 & beta-actin & 4753.3 & 3317.1 & $139.9^{\text {ab }}$ & $242.3^{\text {ab }}$ & 46397316 \\
\hline 13 & gamma-actin & 2580.6 & 3649.9 & $272.5^{b}$ & $10864.9^{a}$ & 54036665 \\
\hline 14 & tubulin alpha-1B chain & 1509.4 & 2470.1 & 4896.3 & $2293.1^{\mathrm{c}}$ & 55976173 \\
\hline 15 & serum albumin precursor & 684.7 & 951.9 & $1233.8^{\mathrm{a}}$ & $6561.9^{a b c}$ & 158138568 \\
\hline
\end{tabular}

All listed substrates were identified by 2-DE and MALDI-TOF-MS analyses. SWISS-PROT and NCBI protein database were used to evaluate MS data. Relative value was significantly different from those of the CON group: ${ }^{a}, p<0.05$; Relative value were significantly different from those of the MOD group: ${ }^{\mathrm{b}}, p<0.05$; Relative value were significantly different from those of the DIO group: ${ }^{\mathrm{c}}, p<0.05$; CON, control; MOD, model rats with learning and memory impairment; DIO, diet-induced obese; DR, diet-resistant; NCALD, Neurocalcin-delta.

Table 2 Primer sequences and fragment length of NCALD gene

\begin{tabular}{cccc}
\hline Primer & Sense primer $\left(5^{\prime}-3^{\prime}\right)$ & Antisense primer $\left(5^{\prime}-3^{\prime}\right)$ & bp \\
\hline GAPDH & TGGAGTCTACTGGCGTCTT & TGTCATATTTCTCGTGGTTCA & 139 \\
& & & \\
NCALD & GCAAATGGAGATGGGACGATAGACT & CTGCCTTGCTGATGTAGCCGTT & 138 \\
\hline
\end{tabular}

GAPDH, glyceraldehyde-3-phosphate dehydrogenase; NCALD, Neurocalcin-delta 


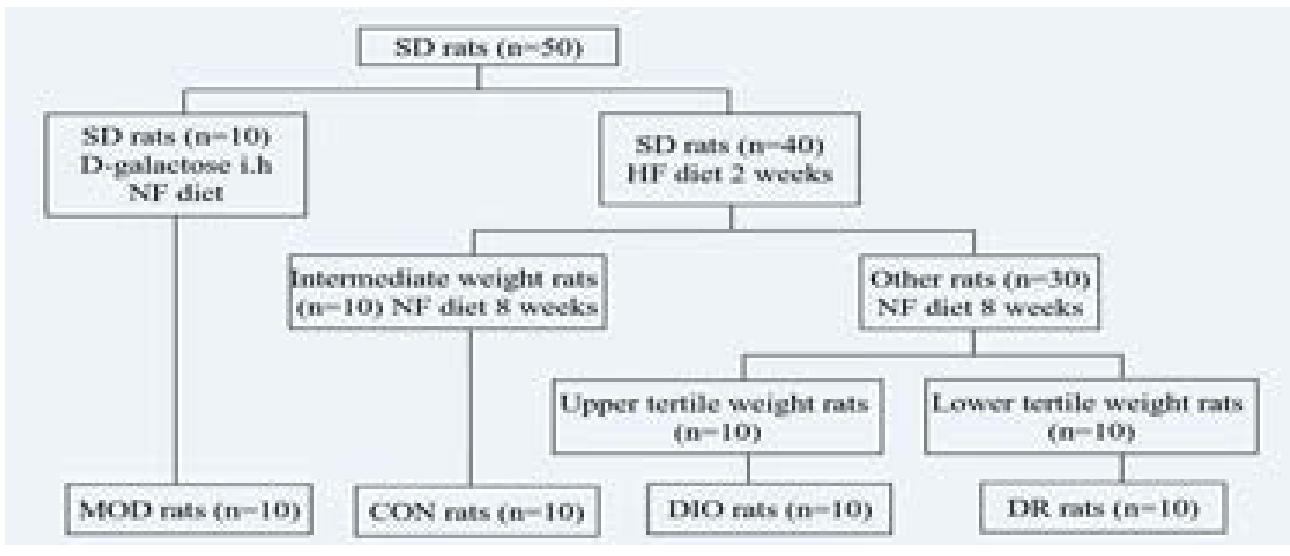

Figure 1 Experimental schedule and groups. CON, control; MOD, model rats with learning and memory impairment; DIO, diet-induced obese; DR, diet-resistant; NCALD, Neurocalcin-delta.

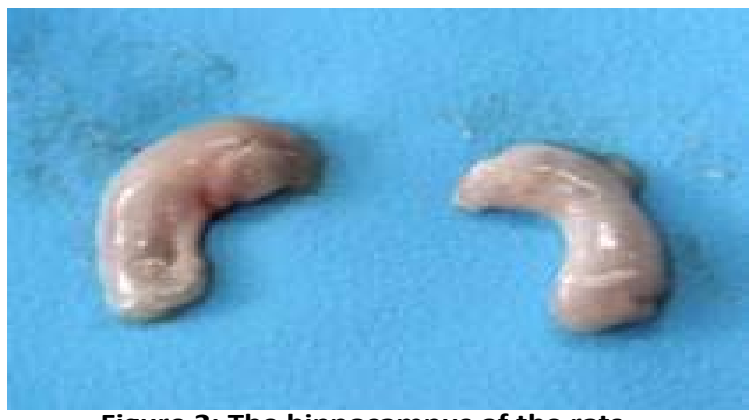

Figure 2: The hippocampus of the rats.

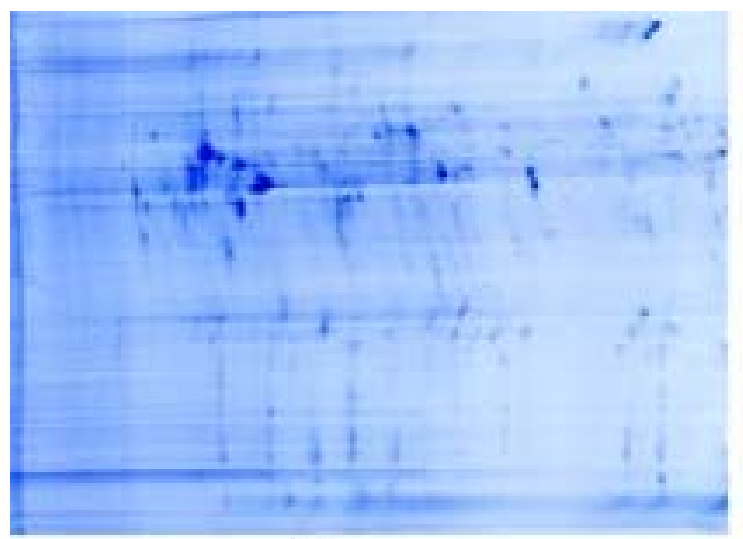

$\cos$
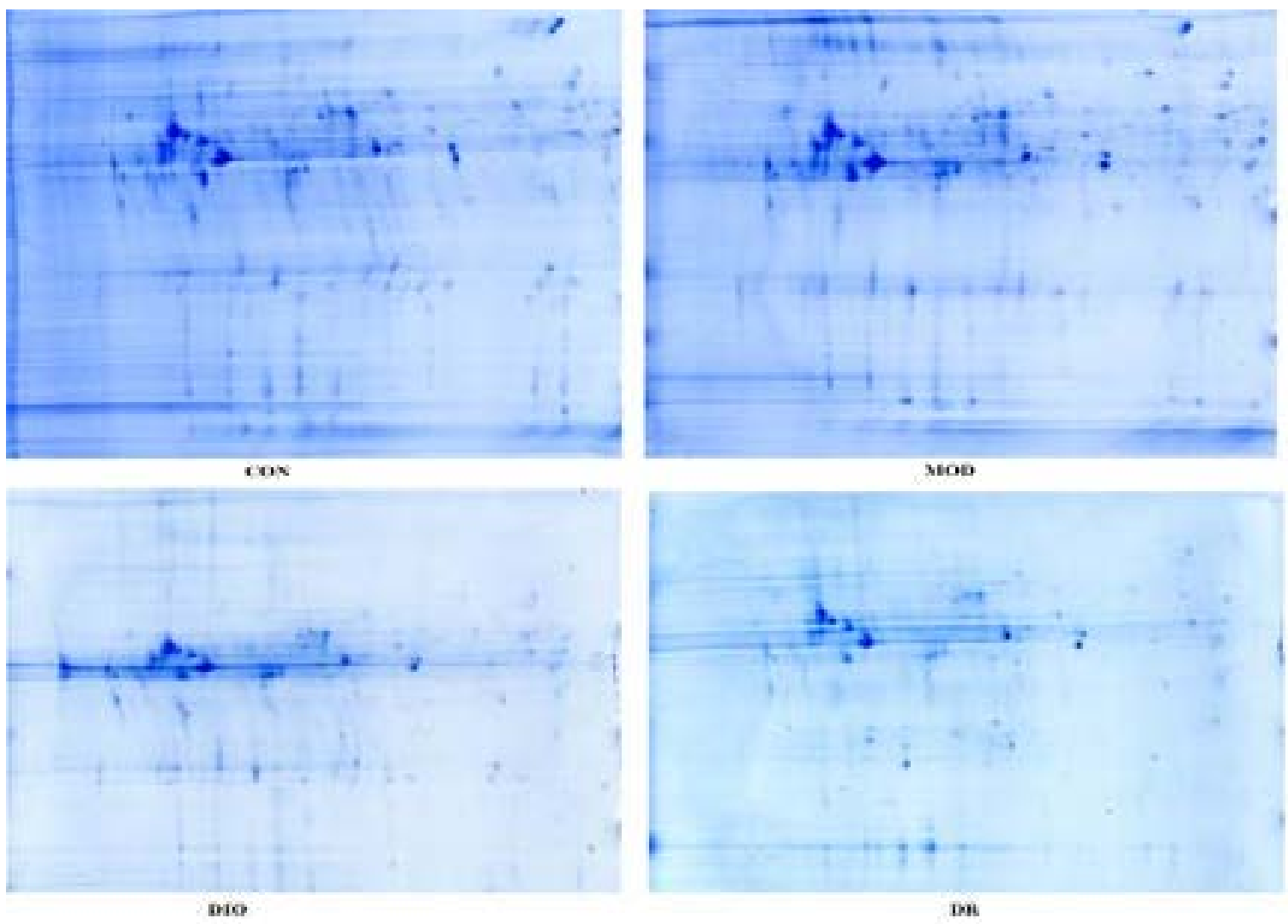

Figure 3: 2-DE images of hippocampus proteins of CON, MOD, DIO and DR rats. CON, Control; MOD, model rats with learning and memory impairment; DIO, diet-induced obese; DR, diet-resistant.

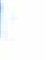


NCALD ELISA assay kit

NCALD concentration in the hippocampus of the rat brain is shown in Table 3. DIO and DR rats had significant lower NCALD concentrations compared to the CON and MOD rats (all $\mathrm{p}<0.05)$.

Table 3. The level of NCALD in brain hippocampus tissue (mean $\pm \mathrm{SE}, \mathrm{n}=6)$ of $\mathrm{DIO}$ and DR rats induced by high-fat diet

\begin{tabular}{cc}
\hline Group & NCALD \\
& $(\mu \mathrm{g} / \mathrm{g}$ prot $)$ \\
\hline CON & $27.06 \pm 2.81$ \\
MOD & $25.74 \pm 2.33$ \\
DIO & $17.97 \pm 2.11^{\mathrm{a} \mathrm{b}}$ \\
DR & $10.53 \pm 0.77^{\mathrm{a} \mathrm{b} \mathrm{c}}$ \\
\hline
\end{tabular}

Mean values were significantly different from those of the CON group: ${ }^{a}, p<0.05$; Mean values were significantly different from those of the MOD group: ${ }^{\mathrm{b}}, p<0.05$; Mean values were significantly different from those of the DIO group: ${ }^{\mathrm{c}}, p<0.05$; CON, control; MOD, model rats with learning and memory impairment; DIO, diet-induced obese; DR, diet-resistant; NCALD, Neurocalcin-delta.

\section{Expression of NCALD in obese rats}

As shown in Figure 4 and 5, the WB results showed that the protein expression of NCALD was significant- ly down-regulated in DIO and DR rats compared with CON and MOD rats (all $\mathrm{p}<0.05$ ), while the mRNA of

NCALD was down-regulated in MOD, DIO and DR rats compared with CON rats (all $\mathrm{p}<0.05)$.
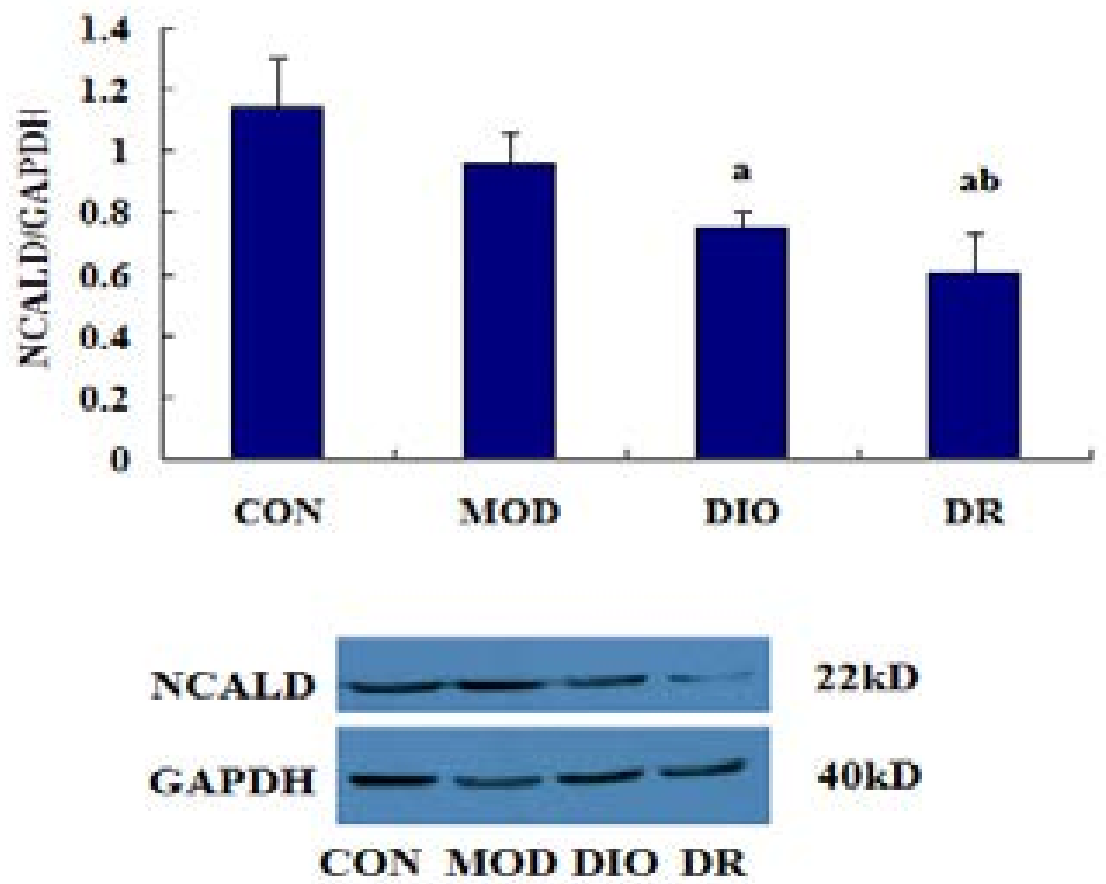

Figure 4: The protein expression of NCALD in DIO and DR rats induced by HF diet. Mean values were significantly different from those of the CON group: ${ }^{a}, p<0.05$; Mean values were significantly different from those of the MOD group: ${ }^{b}, p<0.05$; CON, control; MOD, model rats with learning and memory impairment; DIO, diet-induced obese; DR, diet-resistant; NCALD, Neurocalcin-delta. 

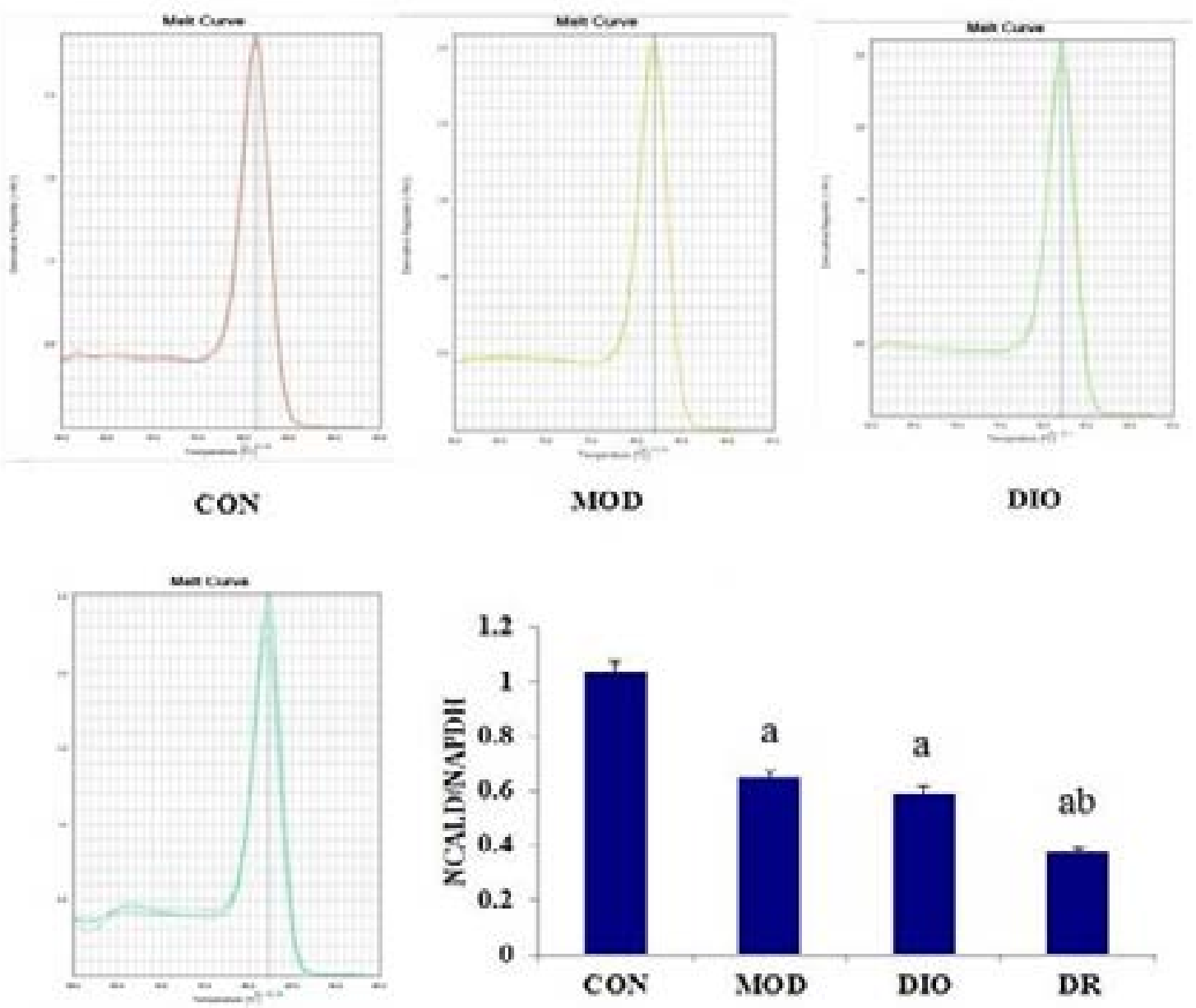

DR

Figure 5: The gene expression of NCALD in DIO and DR rats induced by HF diet. Mean values were significantly different from those of the CON group: ${ }^{a}, p<0.05$; Mean values were significantly different from those of the MOD group: ${ }^{b}, p<0.05$; CON, control; MOD, model rats with learning and memory impairment; DIO, diet-induced obese; DR, diet-resistant; NCALD, Neurocalcin-delta.

\section{Discussion}

In our previous study, rats showed high distinct susceptibility to develop obesity when the rats were fed with a HF diet. In the present study, SD rats were fed with either a HF diet or a NF diet for 10 weeks to generate the CON, DIO and DR rats. The availability of DIO and DR rats are crucial in exploring the mechanisms for development of obesity. D-galactose was injected sub-cutaneously for 10 weeks to establish model (MOD) rats with learning and memory impairments. The final body weight, the perirenal fat, the testicular fat, omental fat and body fat mass of DIO rats were higher than that of DR rats ${ }^{17}$. MOD rats showed impaired learning and memory ability compared with the $\mathrm{CON}$ rats ${ }^{16}$. Alerted protein expression within the hippocampus has recently been implicated in the pathogenesis of obesity-induced memory impairments. Thus, in the present study, we aimed to in- vestigate the differential protein expression in the DIO and DR rats by using 2-D gel electrophoresis and PMF.

Taken together, the differentially expressed spots are presented in Figure 3 and the identified proteins are listed in Table 1. Our findings suggested that the memory-impairing effects of diet-induced obesity might potentially be mediated by down-regulated NCALD within the hippocampus. NCALD is a member of the neuronal calcium sensor (NCS) family of calcium-binding proteins, which mediates signal transduction in response to calcium in neurons ${ }^{29}$. Furthermore, NCALD may be involved in the processes of spermatogenesis, tumorigenesis and diabetic nephropathy ${ }^{30-32}$. In this study, we identified the down-regulated expression of NCALD down regulated in DR rats compared with CON and MOD rats, while NCALD was down-regulated in DIO rats compared with 
CON rats. Furthermore, NCALD concentration in the hippocampus of the rat brains are shown in Figure 2. DIO and DR rats had the lower NCALD concentrations in the hippocampus compared to the CON and MOD rats and the difference were statistically significant. The results also showed that the protein expression of NCALD was significantly down-regulated in DIO and DR rats compared with CON and MOD rats $(\mathrm{p}<0.05)$, while the mRNA level of NCALD was down-regulated in MOD, DIO and DR rats compared with CON rats $(p<0.05)$. These results indicated that NCALD might be a potential memory-related protein in response to $\mathrm{HF}$ diets. In addition, the western blot, real-time PCR and ELISA results showed that the NCALD mRNA and protein were more abundantly expressed in the hippocampus of CON and MOD rats but not in the DIO and DR rats, confirming that the HF diet likely contributed to the inactivation of NCALD in the brain, which in turn led to neuronal damages.

Hpca is a protein that buffers intracellular calcium and prevents calcium-induced cell death ${ }^{33}$. A proteomic approach revealed that Hpca expression wasdecreased in vehicle-treated animals with combined middle cerebral artery occlusion ${ }^{34}$, indicating that its decline was likely to be the performance of damage/lesion. In our study, we found the level of Hpca was also down-regulated, strongly indicating reduced Hpca as a principal pathogenic mediator of obesity-induced memory impairments.

$\beta$-actin and $\beta$-tubulin are essential components of the cytoskeleton and play crucial roles in eukaryotic cells. The actin cytoskeleton functions in the generation and maintenance of cell morphology and polarity, endocytosis, intracellular trafficking, contractility, motility, and cell divi$\operatorname{sion}^{35}$. This result was also consistent with our previous study in the serum proteomics ${ }^{25}$.

Ubiquinol-cytochrome c reductase binding protein, a component of the mitochondrial complex III, has been recently implicated in ROS production ${ }^{36}$. High ROS levels are known to have harmful effects on cell growth, resulting in apoptosis. In this study, Ubiquinol-cytochrome $\mathrm{c}$ reductase binding protein was up- regulated in the brain of DIO rats, indicating that this protein potentially contributed to the ROS production in the hippocampus of the brain in DIO rats.
Alb protein was down-regulated in DR rats compared with other groups, suggesting their different responses to HF diets. Alb was also found in the brain of AD patients. Thus, the serum albumin expressed in the brain of DIO rats but not DR rats might be a factor leading to obesity and obesity resistance.

Lap18, Cnpy2, Hnrnpk and Uchl1 expression levels in the rat hippocampus might be related to obesity-induced memory impairments, but the reasons for the dysregulation of these genes were still not clear.

\section{Conclusion}

In summary, proteomic analysis of rat hippocampus has provided a useful method to detect differentially expressed proteins in obesity-induced memory impairments. We found the potential memory-related factors as a reflection of $\mathrm{HF}$ diet and obesity. Further studies are required to determine the biochemical and physiological functions of these proteins and their relationship with the development of obesity.

\section{Acknowledgments}

This work was supported by the grants from National Natural Science Foundation of China (No. 81102122 and No. 81472982). Ma WeiWei contributed to the drafting of the paper and the implementing of the experiment. Ding bingjie drafted the paper and did the data analysis. Yuan Linhong, Yu Huanling and Xi Yuandi did the western blot and ELISA assay and the data analysis. Lei Zhao contributed to revision of the manuscript. Xiao Rong designed the study and is the corresponding author.

\section{Conflict of interest}

The authors declare no conflicts of interest.

\section{References}

1. Pieniak Z, Pérez-Cueto F, Verbeke W. Association of overweight and obesity with interest in healthy eating, subjectivehealth and perceived risk of chronic diseases in three European countries. Appetite. 2009; 53(3):399-406. 2. Buckman LB, Hasty AH, Flaherty DK, Buckman CT, Thompson MM, MatlockBK, Weller K, Ellacott KL. Obesity induced by a high-fat diet is associatedwith increased immune cell entry into the central nervous system. Brain Behav Immun. 2014; 35:33-42.

3. Hansel B, Roussel R, Elbez Y, Marre M, Krempf M, 
Ikeda Y, Eagle KA, Elisaf M, Bhatt DL, Steg PG. Cardiovascular risk in relation to body mass index and use of evidence-based preventive medications in patients with or at risk of atherothrombosis. Eur Heart J. 2015; 36(40):2716-28.

4. Coughlin SS, Smith SA. The insulin-like growth factor axis, adipokines, physical activity, and obesity in relation to breast cancer incidence and recurrence. Cancer Clin Oncol. 2015; 4(2):24-31.

5. Wang J, Zhu Y, Jing J, Chen Y, Mai J, Wong SH, O'Reilly J, Ma L. Relationship of BMI to the incidence of hypertension: a 4 years' cohort study among children in Guangzhou, 2007-2011. BMC Public Health. 2015; 15(1):782.

6. Gunathilake R, Oldmeadow C, McEvoy M, Inder KJ, Schofield PW, Nair BR, Attia J. The Association between obesity and cognitive function in older persons: how much is mediated by inflammation, fasting plasma glucose, and hypertriglyceridemia? J Gerontol A Biol Sci Med Sci. 2016; 71(12):1603-08.

7. Arnoldussen IA, Kiliaan AJ, Gustafson DR. Obesity and dementia: adipokines interact with the brain. Eur Neuropsychopharmaco 2014; 124(12):1982-99.

8. Anstey KJ, Cherbuin N, Budge M, Young J. Body mass index in midlife and late-life as a risk factor for dementia: a meta-analysis of prospective studies. Obes Rev. 2011; 12(5):e426-37.

9. Lee EB. Obesity, leptin, and Alzheimer's disease. Ann N Y Acad Sci. 2011; 1243:15-29.

10. Lee JW, Rosario E, Jayaraman A, Pike C. Obesity and low testosterone interact to increase vulnerability to Alzheimer's disease pathogenesis. Alzheimer's \& Dementia. 2013; 9 (4 Supplement): 353.

11. Alosco ML, Spitznagel MB, Raz N, Cohen R, Sweet LH, Colbert LH, Josephson R, van Dulmen M, Hughes J, Rosneck J, Gunstad J. Obesity interacts with cerebral hypoperfusion to exacerbate cognitive impairment in older adults with heart failure. Cerebrovascular Diseases Extra. 2012; 2(1):88-98.

12. Kalmijn S, van Boxtel MP, Ocké M, Verschuren WM, Kromhout D, Launer LJ. Dietary intake of fatty acids and fish in relation to cognitive performance at middle age. Neurology. 2004; 62(2):275-80.

13. Francis H,Stevenson R. The longer-term impacts of western diet on human cognition and the brain. Appetite. 2013; 63:119-28.

14. Zhang L, Dasuri K, Fernandez-Kim SO, Bruce-Keller AJ, Freeman LR, Pepping JK, Beckett TL, Murphy MP,
Keller JN. Prolonged diet induced obesity has minimal effects towards brain pathology in mouse model of cerebral amyloid angiopathy: implications for studying obesity-brain interactions in mice. Biochim Biophys Acta. 2013; 1832(9):1456-62.

15. Pratchayasakul W, Sa-Nguanmoo P, Sivasinprasasn S, Pintana H, Tawinvisan R, Sripetchwandee J, Kumfu S, Chattipakorn N, Chattipakorn SC. Obesity accelerates cognitive decline by aggravating mitochondrial dysfunction, insulin resistance and synaptic dysfunction under estrogen-deprived conditions. Horm Behav. 2015; 72:68-77. 16. Ma WW, Yuan LH, Jiang LZ, Ma MY, Li HB, Jia YC, Xiao R. The effect of high fat diet on the ability of learning and memory in obese rats. Chinese Journal of Public Health.2013; 29(8):1179-81.

17. Ma WW, Yuan LH, Yu HL, Xi YD, Xiao R. Mitochondrial dysfunction and oxidative damage in the brain of diet-induced obese rats but not in diet resistant rats. Life Sci. 2014;110:53-60.

18. Beilharz JE, Maniam J, Morris MJ. Diet-induced cognitive deficits: the role of fat and sugar, potential mechanisms and nutritional interventions. Nutrients. 2015; 7(8):6719-38.

19. Molteni R, Wu A, Vaynman S, YingZ, BarnardRJ, Gomez-Pinilla, F. Exercise reverses theharmful effects of consumption of a high-fat diet on synaptic and behavioral plasticity associatedto the action of brain-derived neurotrophic factor. Neuroscience. 2004; 123, 429-40.

20. Castanon N, Luheshi G, Layé S. Role of neuroinflammation in the emotional and cognitive alterations displayed by animal models of obesity. Front Neurosci. 2015; 9:229.

21. Davidson TL, Monnot A, Neal AU, Martin AA, Horton JJ, Zheng W. The effects of ahigh-energy diet on hippocampal-dependent discrimination performance and blood-brain barrierintegrity differ for diet-induced obese and diet-resistant rats. Physiol Behav. 2012; 107: 26-33.

22. Kanoski SE, Zhang Y, Zheng W, Davidson TL. The effects of a high-energy diet on hippocampal function and blood-brain barrier integrity in the rat. $J$ Alsheimers Dis. 2010;21(1):207-19.

23. Molteni R, Barnard RJ, Ying Z, Roberts CK, Gómez-Pinilla F. A high-fat, refined sugar diet reduces hippocampal brain-derived neurotrophic factor, neuronal plasticity, and learning. Neurosci. 2002;112(4):803-14.

24. Wu HW, Ren LF, Zhou X, Han DW. A high-fructose diet induces hippocampal insulin resistance and exacer- 
bates memory deficits in male Sprague-Dawley rats. Nutr Neurosci. 2015; 18(7):323-8.

25. Zhao D, Wang SR, Ma WW, Liu LJ, Sun CH. Alpha1-macroglobulin: a potential obesity-related factor in serum. Med Sci Monit 2008; 14 (3):BR57-61.

26. Kim OY, Shin MJ, Moon J, Chung JH. Plasma ceruloplasmin as a biomarker for obesity: a proteomic approach. Clin Biochem. 2011; 44(5-6):351-6.

27. Joo JI, Choi JW, Yun JW. Proteomic analysis for adipocytes in obesity-prone and obesity-resistance rats. J Biotechnology. 2010; 150(Supplement): 431.

28. Kim DH, Choi JW, Joo JI, Wang X, Choi DK, Oh TS, Yun JW. Changes in expression of skeletal muscle proteins between obesity-prone and obesity-resistant rats induced by a high-fat diet. J Proteome Res. 2011; 10(3):128192.

29. Yang Y, Krishnan A, Viviano J, Venkataraman V. Unraveling the dynamics of the EF1 hand upon $\mathrm{Ca} 2+$ binding in neurocalcin delta. J Biophysi. 2015; 108(2):380a.

30. Krishnan A1, Venkataraman V, Fik-Rymarkiewicz E, Duda T, Sharma RK. Structural, biochemical, and functional characterization of the calcium sensor neurocalcin delta in the inner retinal neurons and its linkage with the rod outer segment membrane guanylate cyclase transduction system. Biochemistry. 2004; 43(10):2708-23.
31. Okazaki K, Obata NH, Inoue S, Hidaka H. S100 beta is a target protein of neurocalcin delta, an abundant isoform in glial cells. Biochem J.1995; 306 (2):551-5.

32. Kamiyama M, Kobayashi M, Araki S, Iida A, Tsunoda T, Kawai K, Imanishi M, Nomura M, Babazono T, Iwamoto Y, Kashiwagi A, Kaku K, Kawamori R, Ng DP, Hansen T, Gaede P, Pedersen O, Nakamura Y, Maeda S. Polymorphisms in the 3' UTR in the neurocalcin delta gene affect mRNA stability, and confer susceptibility to diabetic nephropathy. Hum Genet. 2007;122(3-4):397-407. 33. Jin X, Wang Y, Li X, Tan X, Miao Z, Chen Y, Hamdy RC, Chua BH, Kong J, Zhao H, Xu X. 7,8-Dihydroxy-4-methylcoumarin provides neuroprotection by increasing hippocalcin expression. Neurotox Res. 2015; 27(3):268-74.

34. Koh PO. Estradiol alleviates the ischemic brain injury-induced decrease of neuronal calcium sensor protein hippocalcin. Neurosci Lett. 2014; 582:32-37.

35. Tian J, Han L1, Feng Z, Wang G, Liu W, Ma Y, Yu Y, Kong Z. Orchestration of microtubules and the actin cytoskeleton in trichome cell shape determination by a plant-unique kinesin. eLife. 2015; 4: e09351.

36. Chang J, Jung HJ, Park HJ, Cho SW, Lee SK, Kwon HJ. Cell-permeable mitochondrial ubiquinol-cytochrome $\mathrm{c}$ reductase binding protein induces angiogenesis in vitro and in vivo. Cancer Lett. 2015; 366(1):52-60. 